\title{
Análisis y funciones de las artes plásticas y visuales en la educación*
}

\author{
Analysis and functions of plastic and visual arts in education
}

\section{Resumen}

Este trabajo, presenta los principales enfoques que permiten comprender las funciones de las artes en la actualidad en función de la educación artística, a partir de categorías de análisis concebidas por diversas investigaciones. Este reconocimiento de conceptos se genera con el fin de comprender las dimensiones de percepción y desarrollo de las artes plásticas y visuales, en los estudiantes por medio del proyecto matriz -del que resulta este artículorealizado por el grupo de investigación Educarte de la Facultad de Educación la Fundación Universitaria Católica Lumen Gentium, que tiene su foco de investigación en la ciudad de Cali, Colombia.

Palabras clave: educación artística; currículo; investigación artística.

\begin{abstract}
This article presents an overview of the main approaches that currently allow us to understand the functions of arts in Artistic Education, based on categories of analysis conceived by various investigations. This concept recognition is generated to understand the dimensions of perception and development of plastic and visual arts in students, within the project -in which this article originated- that is part of the Educarte research group of the Faculty of Education of the Fundación Universitaria Católica Lumen Gentium, which focuses in the city of Cali, Colombia for its researches.
\end{abstract}

Keywords: art education; curriculum; artistic research.

* Artículo producto de investigación, proyecto: Análisis de las funciones de las artes plásticas y visuales, en las licenciaturas afines. Unicatólica. Grupo de investigación Educarte.

** Magíster en Estética e Historia del Arte de la Universidad Jorge Tadeo Lozano y maestro en Artes Plásticas de la Universidad Nacional de Colombia. Docente investigador Fundación Universitaria Católica Lumen Gentium, Cali, Colombia. Correo electrónico: laavendano@unicatolica.edu.co; Orcid:0000-0002-7638-013X 


\section{Introducción}

Esta revisión se enfoca en discursos sobre apropiación y aplicación de artes plásticas y visuales para identificar los enfoques, marcos conceptuales y teóricos en los que se inscribe su enseñanza.

En las siguientes páginas se revisan los trabajos más citados en esta área, que consolidan directrices para pensar la educación artística. En primera instancia, se revisó la obra de pioneros, teóricos, artistas, pedagogos y educadores en este tema. De igual manera, se consultó lo escrito por la Unesco, al ser uno de los referentes más importantes con respecto a parámetros educativos. Por último, se revisaron trabajos de investigación en España, México, Chile y Colombia, que evidenciaron tendencias en torno al propósito descrito.

\section{Metodología}

En la presente revisión documental se hizo énfasis en los métodos y otros abordajes de orden conceptual, empleados en los diversos proyectos de investigación estudiados. Lo anterior con el propósito de identificar los referentes, utilizados por los investigadores en la construcción de su metodología, permitiendo ajustar la de este proyecto, al contrastar los resultados obtenidos con los objetivos propuestos en la formulación inicial del presente trabajo. En esta etapa de revisión se evaluaron los trabajos en su conjunto, se les comparó y se establecieron tendencias con el fin de poder otorgarle un sentido a su producción en general y, además, revisar su pertinencia en el contexto de la enseñanza universitaria en los pregrados de Licenciatura Artística en Colombia. En adelante se describen los principales hallazgos.

\section{Investigaciones sobre educación artística en Colombia}

La revisión documental se centró en investigaciones que piensen las funciones del arte para el caso de la educación artística, sin desconocer la importancia de otro tipo de investigaciones que piensen el arte fuera de la educación. Para el caso de Colombia se hallaron los Cuadernos de Educacación 1 y 2, "Educación artística y cultural, un propósito común. Documentos para la formulación de una política pública Colombiana. Ministerio de Cultura" (2007) y Cuadernos de educación artística 2, educación artística y cultural un propósito en común. Pensamiento artístico y estética de la experiencia: repercusiones en la formación artística y cultural de Francisco Javier Gil Marín (2007).

En el primer cuaderno, la educación artística se aborda desde la educación no formal en instituciones de básica primaria, básica secundaria y media (Ministerio de Educación Nacional, 2007). Aquí podemos apreciar que el área de educación artística se enfoca en la obtención de un producto artístico, dejando de lado los procesos. De igual manera, el documento da cuenta de cómo, en la educación superior, el arte se asume como un capital cultural y ontológico, pero sin ningún tipo de pretensión pedagógica.

En el segundo cuaderno Gil Marín (2007) presenta el panorama de la educación artística como medio para encaminar la educación del país hacia lo cognitivo, panorama en el que los elementos creativos se asumen como procesos pedagógicos.

Juan Antonio Cuellar y María Sol Effio (2010) realizaron una investigación sobre la enseñanza de la educación artística, a partir de los lineamientos emitidos por el Ministerio de Educación Nacional de Colombia -MEN- propuesto para los docentes de básica primaria, básica secundaria y media. En el documento mencionan tres formas en las que se imparte la educación artística: 1) como formación de artista, 2) como vehículo para la formación de la persona y 3) para la formación en el arte. Esta investigación no contempla la incidencia que la formación de licenciados en educación artística puede tener en la enseñanza de una educación artística de calidad, orientada a la formación integral de los niños y jóvenes. 
En "Notas para una historia de la educación artística en Colombia en el siglo XX" Miguel Huertas (2016) muestra cómo la educación artística pasó de ser una enseñanza para hacer arte, a ser una enseñanza por el arte, en un contexto en el cual se le demerita. El artículo da cuenta de la manera en que la educación artística ha evolucionado desde el cumplimiento del canon decimonónico que plantea unas normas de "buen gusto" en la apreciación del arte, hasta la concepción de un artista crítico y pensante.

La década de 1990 -extraordinariamente compleja-cerró el siglo con un gran impulso al pensamiento centrado en las formas de enseñanza del arte. Mencionamos solo dos grandes movimientos: 1) la construcción en el Ministerio de Educación (Ministerio de Educación Nacional, S.f.), liderada por María Elena Ronderos y basada en un movimiento de reflexión nacional, de los mismos profesores sobre los nuevos lineamientos curriculares para la educación artística. Dicha publicación, a pesar de haber sido impugnada dado a los cambios que se introdujeron al texto a último momento, sigue siendo un documento de referencia esencial; 2) la reforma del Programa de Artes Plásticas de la Universidad Nacional (reforma Mockus-Páramo de 1993) en la que se plantea como misión de la escuela, no la sumisión a algún canon o la transmisión de técnicas, tradiciones, estilos o procedimientos específicos, sino la formación de un "artista pensador" capaz de tomar distancia crítica "de la cotidianidad de la vida social" (Huertas, 2016).

Este panorama muestra que la educación artística en Colombia ha sufrido un cambio de paradigma, que parte de lo académico e incide en los conceptos de arte en la contemporaneidad, para ser apropiado por los docentes en sus clases y su aplicación al momento de subjetivar y dar un discurso propio sobre la profesión.

Las políticas de los ministerios de Educación y de Cultura en Colombia permiten inferir el tipo de caminos señalados a nivel gubernamental para la educación artística en el país. El estudio generado por el Ministerio de Cultura, en 2005, generó una prospectiva sobre la educación artística en el país, incluido en el Cuaderno de Educación Artística 1 (Ministerio de Educación Nacional, 2007). Este cuaderno contiene diferentes investigaciones y análisis de la educación artística en Colombia, así como su proyección en la educación colombiana y cómo se puede mejorar con desarrollos desde diferentes ámbitos y perspectivas, teniendo en cuenta las bases de una educación pluricultural.

En el 2010 se generó el documento 16 del Ministerio de Educación, Orientaciones Pedagógicas para la Educación Artística en Básica y Media, el cual reflexiona en torno a la relación de la educación artística, las competencias básicas y el plan de estudios. Allí, el arte se convierte en un medio o recurso para enseñar en las distintas áreas de conocimiento. Es decir, se propone un conjunto de métodos cuyo fin es la apropiación intelectual del patrimonio a través del desarrollo de aptitudes sensibles e inteligentes, definidas desde un plano sociológico como vías de acceso a la expresión de una cultura para el conocimiento individual y social, la identidad, historia y memoria. Se trata de un modelo que trata de mejorar el entorno educativo por medio del arte enfocado en una pedagogía cultural, para percibir nuestro entorno de una manera más sensible y poder enfocar ese conocimiento en las distintas áreas existentes para el aprendizaje.

La relación hallada entre las investigaciones descritas y los documentos de la Unesco y de los Ministerios de Educación y Cultura, en Colombia, muestran una coincidencia en la afirmación de que existe en la definición del arte un factor de cambio en la sociedad. El arte se propone como vehículo de tipos alternativos de conocimiento, con lo que se postulan funciones de tipo social para el arte en la educación. De ahí se postula que el arte debe afianzar el sentido crítico sobre su contexto, tanto en perspectiva histórica de sí mismo, como en perspectiva contemporánea. En resumen, 
la hoja de ruta diseñada por la Unesco y lo propuesto por los ministerios mencionados concuerdan en que otorgan al arte las funciones de comprensión de la inclusión social, diversidad cultural, patrimonio, cultura, identidad y memoria.

\section{Un referente en México}

En México Oliva Abarca (2015) publicó la investigación "La función cognitiva de las artes en la sociedad contemporánea", su texto cuestiona las razones por las cuales el arte no comporta un valor cognoscitivo específico. El texto aduce que, en la actualidad, la creación artística contemporánea se encuentra desvinculada conceptualmente de los programas, que no enseñan arte para crear artistas de galerías, de tal forma que encontramos artistas y públicos alejados discursivamente de los contenidos:

Una posible respuesta es la progresiva disociación entre la creación artística y la sociedad; el arte moderno, como indicó Ortega y Gasset, recurre cada vez más a una suerte de introspección, y se convierte en un arte comprensible sólo [sic] para los artistas, alejado del público y del gusto de la gente común y corriente. (Oliva Abarca, 2015, p. 37)

El texto describe la cualidad de la función cognitiva del arte por medio de características que se dan en los diferentes entornos sociales en los que circula. Esto quiere decir que tiene la capacidad de ser diferente para todas las personas y sus representaciones van ligadas a la cultura al constructo social, ya que su significación es flexible, lo cual genera diferentes soluciones o perspectivas de acuerdo con las personas.

\section{Un referente en Chile}

El Gobierno de Chile, por medio del Consejo Nacional de Cultura y las Artes, presentó la investigación "El aporte de las artes y la cultura a una educación de calidad: Caja de herramientas de educación artística" (Rojas, 2016), con la que buscaba generar una reflexión colectiva sobre el valor y los aportes de la educación artística y cultural en la construcción de una educación de calidad integral. Los autores hicieron una descripción del aporte de las artes y la cultura a la educación, precisaron qué aspectos se deben fomentar en la educación desde la integralidad; plantearon los beneficios de la formación en educación artística y realizaron reflexiones desde tres actividades constituidas por preguntas orientadas al diagnóstico de la enseñanza actual de la educación artística, los aspectos que se deben modificar y el impacto que tiene esta enseñanza en el mejoramiento de la calidad de dicha área.

Los interrogantes se orientan a personas directamente implicadas en la pedagogía artística, a los elaboradores del Proyecto Educativo Institucional y administradores de la educación, cultores y sujetos implicados en la educación artística no formal. Los autores definen los aspectos que deben fortalecerse para lograr una educación artística de calidad, aclarando que no es una labor exclusiva de la escuela ni del profesor que orienta el área, es una labor que exige el acompañamiento de las políticas públicas, de la comunidad y de la cultura.

Para articular la guía se toman dos experiencias de procesos de la educación artística formal: un liceo y una escuela de música; y dos de la educación artística no formal: un circo y un centro cultural. En estas experiencias se muestran los antecedentes, beneficios, planes y logros destacados en dichos procesos. Una quinta experiencia, con la que se articula toda la guía, consiste en exponer cómo se pudo dar apertura a un espacio en el cual se integra la educación artística formal y la educación artística no formal: una semana internacional de la educación artística incorporada al calendario escolar, demostrando que ambos tipos de educación artística suman en el desarrollo de una política de calidad.

\section{Un referente en España}

Dentro de esta revisión se pudo constatar que, durante las últimas décadas, España presenta un 
panorama de interés sobre este tipo de investigaciones. Esto lo convierte en uno de los países con mayor producción en esta área. Se pueden citar aquí a tres de los autores con mayor producción textual: Imanol Aguirre (2006), Javier Abad (2009) y María Acaso (2009), quienes proponen un uso aplicado del arte en la educación desde el pensamiento crítico social.

El investigador Imanol Aguirre encontró que los modelos más utilizados para la enseñanza en educación artística son el logocentrista, el filolingüísta y el expresionista, siendo este último el más utilizado. Según Aguirre, el modelo expresionista se ha arraigado, de tal manera, en el ámbito de la educación que se convirtió en uno de los principales motivos por los que durante tanto tiempo en la educación artística se ha carecido de propuestas teóricamente solventes y metodológicamente eficaces. Para él, la llamada "pedagogía cultural" está ocupando el papel que anteriormente tenía la "pedagogía escolar". Los educadores se han lanzado a la tarea de repensar la escuela y proponen que abandone su función tradicional reproductora de saberes y que se ocupe de preparar a los individuos para hacer un uso crítico y democrático de las informaciones que hoy todos los ciudadanos tienen a su alcance.

\section{El arte como agente social}

Javier Abad propone una función social del arte en "Usos y funciones de las artes en la educación y el desarrollo humano" (2009). Dicha función es de tipo social y está relacionada con la participación ciudadana desde la vinculación y fortalecimiento de lazos familiares y comunitarios. Según Abad, resulta pertinente que, por medio de las narraciones que hace el arte, se reconstruya la percepción de nosotros mismos en el mundo. Cada cultura ofrece a sus miembros la posibilidad de asumir modelos de identidad y comportamiento. Mediante esta función de las artes, el proyecto escolar puede ingresar en una nueva dimensión narrativa que dialoga con las situaciones cambiantes que afectan tanto a los sujetos pedagógicos, como a las relaciones sociales, las representaciones culturales y los conocimientos, entendidos no solo como una situación de intercambio en los procesos de enseñanza y aprendizaje (en el peor de los casos, de dominio), sino como una práctica de política comunitaria para el desarrollo humano (Abad, 2009).

\section{El arte como generador de pensamiento crítico sobre la realidad}

Dentro de esta función, la autora española María Acaso en la obra "La educación artística no son manualidades" (2009) plantea el uso del arte, en la educación, como un medio para la implementación de un pensamiento crítico frente a los mensajes audiovisuales. Sus postulados apuntan a la comprensión de una cultura visual, entendida esta como el análisis de la cultura, más allá de lo que tradicionalmente recibe el nombre de arte. La autora plantea una actitud crítica frente a lo que enseña la educación artística en la escuela. Ella lleva a cabo sus investigaciones -fruto de la experiencia de sus clases- e implementa sus metodologías pedagógicas con sus estudiantes. De esa manera, puede dar cuenta de que lo teorizado es llevado a la práctica. Del mismo modo, manifiesta que es clave generar un sentido crítico sobre la cultura visual por parte de los docentes en la impartición de la educación artística. En sus postulados se pone en juego una actitud ética sobre la responsabilidad del arte frente a la tarea de alfabetizar ya no solo visualmente, también discursivamente, sobre la representación de la realidad que crean las imágenes.

En los siguientes apartados se presentan los campos teóricos que permiten complementar la caracterización de estas funciones desde discursos consolidados.

\section{Discursos ontológicos y holísticos}

En esta exploración hay que hablar de dos autores clásicos que generaron un camino de investigación sobre educación artística. El primero 
de ellos es el trabajo de Hebert Read y Horacio Flores Sánchez (1957), en el que se consideró el arte como elemento principal en la evolución, avance social y cultural de una sociedad, lo asumió como parte de la existencia y el desarrollo del ser humano. Para Read, el arte se convierte en el soporte de la cultura humana, desde lo ontológico; adquiere un sentido espiritual, por lo que el uso de este tipo de funciones no es medible ni cuantificable, porque corresponde al plano de lo filosófico y del ser (Read y Flores Sánchez, 1957).

De acuerdo con lo anterior, el arte, en mi opinión, ha seguido siendo una clave para la supervivencia. Por mucho que se lo haya presentado bajo el disfraz de un falso idealismo y un refinamiento intelectual, sigue siendo la actividad por medio de la cual se conserva alerta nuestra sensación, viva nuestra imaginación, penetrante nuestra facultad de razonamiento (Read \& Flores Sánchez, 1957). Para este autor, pionero en educación artística, el arte se estudia como herramienta para la aprehensión del mundo y como recurso simbólico, capaz de convertir la realidad en pensamiento.

El segundo autor -clásico en educación artística-, es Eisner (1933-1962). Él identificó la educación en artes como un proceso cognitivo desde el cual las personas aprenden a crearse a sí mismas. Su discurso se orienta desde la disposición biológica del ser humano y la incidencia de la experiencia en la formación de la mente. Específicamente, en las acciones de conceptualizar, imaginar y representar, desde las cuales el arte puede sacar partido. En segundo lugar, aborda los aportes del arte, dentro de las prácticas artísticas, las cuales se refieren al aporte del arte en la transformación personal y de la conciencia, en estas se dan dos procesos: la experiencia del artista y los procesos vinculados a la creación de una obra de arte. En el segundo aspecto está el modo en que las artes afectan la conciencia, no desde la experiencia del artista, sino a los espectadores o desde el rol de estudiantes de arte.
Para Eisner (2004), las artes aportan los elementos más importantes en la transformación de la conciencia, por medio del cultivo profundo de los sentidos: estimula la imaginación, ofrece experiencias nuevas, proporciona ocasiones y materiales para abordar problemas, brinda medios para expresar significados que, si bien no siempre se pueden ver, sí se pueden sentir.

Estos dos pioneros de investigación en educación artística presentan el arte como generador de políticas culturales en las cuales lo experiencial, lo sensorial y lo cognitivo, hacen un todo para las disciplinas basadas en arte y educación.

\section{Campos teóricos sobre educación artística}

\section{La enseñanza por medio del arte. El arte aplicado en otros campos de conocimiento}

Para Eisner (2004) el conocimiento artístico no ofrece posibilidades para la generalización y se trabaja solamente con particularidades. Está concepción equivocada le permite a Eisner justificar que no solamente podemos encontrar generalizaciones científicas o naturalistas, sino también generalizaciones producidas por el conocimiento artístico y que se denominan universales concretos, los cuales deben estar en la clasificación de generalización científica, generalización naturalística y generalización artística. "Estos universales [concretos] son aquellas poderosas imágenes que nos ayudan a captar significados diversos, al funcionar como imágenes canónicas a través de las cuales organizamos nuestra concepción del mundo." (Eisner, 2004, p. 26)

\section{El arte como vehículo de desarrollo integral}

Read concibe la realidad como una experiencia orgánica total (Read y Flores Sánchez, 1957), esta manera de entender el mundo se hace fuertemente evidente en el proceso que los niños desarrollan de cara al mundo, puesto que no diferencian con claridad imagen y percepción, es lo que el autor nombra como 
"consciencia unificada" (pensamiento eidético). Es decir que no se da todavía la formación de conceptos abstractos; estos surgen después en "una conciencia escindida" (pensamiento logicista), lo que significa que, al dejar la inocencia prístina o las cosas infantiles, su mundo se compone de fuerzas discordantes entre imágenes y realidad, conceptos y sensación, lógica y vida. Es en este punto en el que se resalta el papel del arte pues le permite al niño recuperar y mantener una conciencia integrada.

Al arte en la educación también se le otorga la función de experiencia sensible. En esta reflexión de conceptos teóricos nos atrevemos a darle a su uso el nombre de estéticas (en tanto experiencias sensibles del estudiante).

\section{La estética de la percepción}

Para Eisner (2004) esta categoría es una capacidad necesaria para el aprendizaje artístico y el currículo la debe desarrollar en el ámbito del dominio crítico. Esto significa que los programas de educación artística deben desarrollar en el estudiante la sensibilidad y la capacidad visual para percibir y ver las cualidades y relaciones de las formas visuales -en especial de las obras de arte- con respecto a su carácter estético y expresivo o "forma estéticamente fundamentada".

\section{La estética de la experiencia}

Read (1957), es tal vez el referente teórico que nos permite entender con mayor claridad esta categoría, ya que para él la expresión es el principal medio de comunicación del ser humano. En este sentido, explica que todas las actividades que un niño lleva a cabo en un proceso de expresión espontánea son "por propia y libre voluntad", por ejemplo, los dibujos o pinturas que hacen cuando tienen un lápiz o un pincel. Del mismo modo, explica, apoyándose en Montessori, que el dibujo es la técnica artística más inmediata que le permite a un niño o individuo expresarse y/o comunicarse, así mismo, expone los siguientes interrogantes: "¿acaso el producto de esta actividad es, en algún sentido, inspirado; ¿puede, en algún sentido de la palabra, describírselo cómo artístico? ¿0 es, como lo sugiere Löwenfeld, una mera forma de juego?" (Read y Flores Sánchez, 1957).

\section{La estética de la comunicación}

En cuanto a la comunicación, para Read (1957), es una actividad social que implica influencia, integración y una adaptación social. Dicho proceso inicia con el destete y se considera que se completa cuando el individuo empieza a formar parte de una o varias unidades sociales -familia, religión, nación, etc.-. De esta manera. la comunicación influye en el desarrollo individual y permite superar la angustia de la separación generada por el destete. Es así como en adelante, el individuo en todas las actividades que realice -arte, religión, ciencia- buscará un "sustituto" para restablecer "ese amor maternal" que perdió en la infancia. Este análisis de la comunicación le permite a Read afirmar que la expresión no es una efusión por sí misma, o un correlato de una percepción, es más bien -teniendo en cuenta a Suttie-: "una propuesta que exige respuesta de los demás" (Read y Flores Sánchez, 1957). Es decir, las actividades expresivas del niño, especialmente el dibujo, son una extensión de sus manifestaciones hacia el mundo exterior.

\section{La estética del sujeto y la sociedad. El cuida- do de sí mismo}

Para Read (1957), un efecto de la enseñanza sobre los procesos mentales es un consecuente crecimiento de la mente. Read define este efecto como un proceso de aprendizaje que se da como resultado del impacto del ambiente y de la sociedad sobre la sensibilidad del niño. El autor considera que no se puede limitar el concepto de "maduración" a aquellos cambios físicos o mentales resultantes del crecimiento o desarrollo orgánico, ya que aparte de la conducta generada por los instintos heredados, el niño también "aprende por experiencia". Describe, además, que las cuatro formas de crecimiento o desarrollo de la mente, planteadas por Koffka, son formas de percepción que dan como resultado imágenes y sensaciones que, a su vez, conllevan sentimientos. De acuerdo 
con Read estos son los materiales elementales con los cuales se construye el mundo y la forma de comportamiento en el mundo.

Al tener en cuenta este crecimiento y desarrollo de la mente con dichos materiales es que Read considera que la finalidad de la educación es ayudar al niño en el crecimiento y desarrollo de su aprendizaje y maduración. Así mismo, dicho proceso educativo, de crecimiento de la mente con dichos materiales debe permitir determinar si se está resolviendo el problema de los métodos educativos y si son los correctos y adecuados para lograr esta finalidad (Read y Flores Sánchez, 1957, págs. 75-77).

\section{La estética del hacer. El producto/ la techné}

Para Eisner, uno de los problemas de la educación y de la educación artística es que se da mayor importancia al producto artístico como único resultado final y se desestima el efecto que puede cumplir la producción artística como una función que ayuda al desarrollo humano.

\section{a Unesco}

Es relevante, dentro de esta actualización de investigaciones, revisar los documentos orientadores de la Unesco, porque a pesar de no ser muy similares a este proyecto, sí son documentos que se convierten y erigen a manera de políticas educativas que son fuente de citación obligada en esta temática. En la Agenda de Seúl: Hoja de ruta 2010 Se propone:

La educación artística debe desempeñar una función importante en la transformación constructiva de los sistemas educativos, que se esfuerzan por satisfacer las necesidades de los estudiantes en un mundo que se transforma con rapidez, caracterizado, por una parte, por notables adelantos tecnológicos y, por la otra, por injusticias sociales y culturales de difícil solución. (Unesco, 2010, p. 2)

Si se toman en cuenta estas indicaciones de la Unesco en diálogo con lo que plantea el investigador español Abad, encontramos que:
La experiencia estética permite establecer relaciones sensibles con las estructuras que establecen y conforman las personas con la realidad, con los otros y consigo mismas, en la medida en que permiten imaginar e inventar otras posibles formas de pensar y representar el futuro. La educación estética resulta relevante en la construcción de formas colectivas de subjetividad en todos los escenarios enfocados al desarrollo del ser humano, teniendo como principales ejes: la constitución del sujeto (entendido como un movimiento permanente en relación a los otros), las relaciones y compromisos con la ética, la afectividad y la actividad creativa en contextos de enseñanza y aprendizaje (la educación artística implica, de esta manera, también compromisos, ya que no existe el aprendizaje sin promover cambios para la igualdad). (Abad, 2009)

Podemos inferir que la enseñanza del arte está actualmente vinculada al carácter social de sus aportes. Sus funciones han pasado de lo técnico, mecánico y/o académico, a un uso social y comprometido con su contexto.

Estas investigaciones dan cuenta de que se han establecido dos categorías: lo pedagógico y lo artístico, en la primera se reconoce el valor educativo del arte, se puede reflexionar sobre este mismo como medio o como generador de fines específicos, estos últimos van relacionados con el acceso al conocimiento en relación consigo mismo y con los diversos campos de conocimiento en la sociedad que le rodea. En la segunda categoría, el arte se establece como propiciador de un estado sensible.

Por otra parte, en los textos revisados hay una relación del arte con un fin determinado en la cual no se especifica el proceso pedagógico-artístico en sí, sino que se evidencian los logros que puede generar, como desarrollo humano, autoconocimiento, comprensión de los otros campos de conocimiento (ciencias naturales, ciencias sociales, matemáticas, lenguaje y comunicación) o promoción de beneficios sociales. 
A partir de esta revisión podemos dar cuenta de cómo al arte se le exige que cumpla varias funciones que van desde lo mínimo cognitivo hasta procesos de capitalismo estético. La educación artística no es ajena a estas tensiones. Se puede observar que las funciones que se le asignan al arte dentro de la educación, están ligadas al desarrollo de la creatividad y el pensamiento crítico, de igual manera, se busca que con la aplicación de las artes en la academia se consiga una formación integral en lo pedagógico, artístico y social.

Estos enfoques y experiencias a las que se ve sometido el arte en su desarrollo como medio y fin, permiten a los estudiantes cuestionarse su esencia como experiencia estética, valorando lo que se hace, y para qué se hace en el desarrollo de la educación artística en las instituciones. La figura del artista se ve entonces como un gestor de procesos que forma desde una integralidad, siendo esta un eje transversal de sus funciones.

\section{Conclusiones y recomendaciones}

Encontramos en esta revisión que la experiencia estética es parte del desarrollo cognitivo en las funciones de las artes, como se menciona en los documentos del Ministerio de Educación Nacional', que dan cuenta de que los objetivos del arte en su enseñanza, es decir, el arte con fines pedagógicos, se utiliza como un medio para llegar a otros objetivos, estos se pueden subdividir en otras categorías que han dado nombre al proceso artístico-pedagógico, y en otras el arte simplemente se comprende como una vía para lograr unos fines específicos que abarcan diversos aspectos del sujeto mismo y del sujeto social. La relación entre experimentación y desarrollo del pensamiento creativo lleva a nuevas maneras de enseñanza para la educación artística en Colombia y se convierte en la base del pensamiento crítico y la experimentación.

La otra función del arte que se puede identificar es como hecho artístico, en la educación se le aborda en términos de arte como fin. En esta forma o función se encuentra: 1) el arte como producto, aquí se instruye sobre este en términos de una creación masificada y con objetivos claros de marketing;2) el arte como experiencia estética, en la que la búsqueda de un estado sensible es su única finalidad.

La otras funciones pedagógicas se dan desde lo experiencial, es decir lo que sucede en el sujeto, teniendo en cuenta que la experiencia es un medio para fines educativos; desde lo perceptivo, como medio de aprehensión de la realidad a través de los sentidos; como factor para el desarrollo humano, por medio de estrategias adecuadas para que la persona adquiera las capacidades y habilidades cognitivas, psicológicas y motrices, con el fin de cumplir con los parámetros de cada etapa de vida; como construcción de sí mismo, quiere decir que el arte sirve como un camino de autoconocimiento, un ejemplo de esta función es el arteterapia, que permite la construcción de posibles mundos de autoconocimiento y cuya finalidad es la sanación; como reflexión crítica para la lectura de la realidad, que proporciona herramientas de deconstrucción y análisis para entender el contexto político social y construye un ser crítico; como medio para conocer la realidad del mundo a través de su aprehensión fáctica, aquí el arte se utiliza con el fin de comprender la naturaleza de las cosas, generar nuevo conocimiento en los sujetos; también aplicado a otros campos del conocimiento, en este caso su función es que, por medio de la didáctica y la lúdica, se involucre en el aprendizaje de matemáticas, ciencias naturales, ciencias sociales, lenguaje y comunicación; en lo social, en términos del impacto y generación de cambio en la sociedad.

Lo anterior quiere decir que las investigaciones sobre la artes plásticas y visuales en la educación se han trabajado desde discursos que entienden estas funciones como: lo expresivo, visto como la posibilidad de permitir que los sujetos se expresen desde lo

1 Al respecto, pueden verse los textos ya citados "Educación artística y cultural, un propósito común. Documentos para la formulación de una política pública Colombiana. Ministerio de Cultura" (2007), "Lineamientos curriculares para la Educación Artística” (S.f.) y "Orientaciones pedagógicas para la educación artística en básica y media" (2010) 
plástico; la formación integral, en la cual lo holístico prima y la función del arte aspira a construir un ser o un ente total; lo social, el arte como motivador de cambio social en términos de impacto, con el fin de generar un cambio en la sociedad; lo visual, una aplicación de lectura crítica sobre los mensajes que circulan de forma audiovisual en el mundo.

De igual forma se le da al arte la función de vehículo para el autoconocimiento, o la capacidad de crearse a sí mismo como sujeto, allí la construcción y reparación de posibles mundos se erige como una finalidad. En la categoría del arte como conocimiento se considera al arte por sí mismo como conocimiento autónomo e independiente. En el arte aplicado a otros campos de conocimiento, su aplicabilidad se puede dar en otro tipo de asignaturas como lo son matemáticas, ciencias naturales, ciencias sociales, lenguaje y comunicación (entiéndase como lenguas, español e inglés) ${ }^{2}$, en las que se utilizan generalmente como didáctica.

Se puede concluir que el arte ha sido utilizado con fines educativos, principalmente, de dos maneras. En una primera etapa su utilidad correspondía a la creación ontológica e individual del ser, como se observó en los pioneros de la investigación artística. En una segunda etapa, en la educación se le otorga al arte la función de herramienta social, vista como una experiencia de comunidad o sentido crítico sobre los mensajes audiovisuales producidos y recibidos por toda la sociedad.

Se distinguen dos categorías principales de las funciones del arte en la educación, la primera es la pedagógica, puesto que el arte se comprende como medio para lograr fines específicos de conocimiento sobre el mundo y mismo el sujeto. Aquí el arte se emplea como herramienta educativa. La segunda es la artística, su objetivo es la experiencia sensible en sí. En esta última, se plantea una vertiente que asume el arte como producto dentro de un mercado.

En la categoría pedagógica se reconoce el valor educativo del arte, se puede reflexionar sobre el arte como medio o generador de fines específicos relacionados con el acceso al conocimiento en la relación del sujeto consigo mismo y los diversos campos de conocimiento y con la sociedad que le rodea. En la segunda categoría -pedagógica- el arte se establece como propiciador de un estado sensible.

La categoría pedagógica se contrapone a la segunda, la artística, ya que en esta última hay un sentido totalmente distinto, no genera una educación para el arte. En ella, el arte emerge como producto de creación masificada y con objetivos claros de marketing. Podemos entonces inferir una subcategoría dentro de esta categoría artística: lo estético, entendido como la búsqueda de un estado sensible como único fin.

Aunque podrían ser conceptos similares, hay que tener claro qué suponen frente a la educación artística para el desarrollo de la investigación. Para finalizar, quedan los siguientes interrogantes: irealmente se enseña el arte, o son las prácticas o experiencias artísticas las que permiten un acercamiento al arte como forma de sensibilización y acercamiento al conocimiento? De acuerdo con los postulados revisados, encontramos que en la contemporaneidad se busca el conocimiento sensible, la formación artística, la educación y la experiencia estética.

$\mathbf{2}$ El español y el inglés son las dos lenguas de enseñanza obligatoria en la educación básica y media en Colombia por instrucción del Ministerio de Educación Nacional. 


\section{Referencias}

Abad, J. (2009). Usos y funciones de las artes en la educación y el desarrollo humano. Educación artística, cultura y ciudadanía, 17-23.

Acaso, M. (2009a). Nuevas prácticas en la enseñanza de las artes y la cultura visual. Cataratas.

Acaso, M. (2009b). Retando a los retos. En M. Acaso, La educación artistica no son manualidades (pp. 112128). Catarata.

Aguirre, I. (2006). Modelos formativos en educación artística: Imaginando nuevas presencias para las artes en educación. Foro Virtual Permanente del Congreso Regional en Formación Artística y Cultural para América Latina y El Caribe.

Cuellar, J. A., y Sol, M. (2010). Orientaciones pedagógicas para la educación artistica en básica y media. Ministerio de Educación Nacional.

Eisner, E. W. (2004). El arte y la creación de la mente: el papel de las artes visuales en la transformación de la conciencia. Paidos Iberica Ediciones.

Gil, F. M. (2007). Pensamiento artístico y estética de la experiencia: repercusiones en la formación artistica y cultural. http://www. sinic. gov.co/ SINIC/Publicaciones/PublicacionesDetalle. aspx.

Huertas, M. (2016). Notas para una historia de la educación artística en Colombia en el siglo XX. Revista Credencial. http://wuww.revistacredencial.com/credencial/historia/temas/notas-para-una-historia-dela-educacion-artistica-en-colombia-en-el-siglo-xx
Ministerio de Educación Nacional. (2007). Educación artística y cultural, un propósito común. Documentos para la formulación de una política pública Colombiana. Cuadernos de Educación Artística 1, 93-131.

Ministerio de Educación Nacional. (s. f.). Lineamientos curriculares para la Educación Artística.

Oliva Abarca, J. E. (2015). La función cognitiva de las artes en la sociedad contemporánea. Imaginario Visual, 5(9), 32-41.

Read, H., y Flores Sánchez, H. (1957). Imagen e idea: la función del arte en el desarrollo de la conciencia humana. Breviarios del Fondo de Cultura Económica.

Rojas, P. (2016). El Aporte de las Artes y la Cultura a una Educación de Calidad Caja de Herramientas para la Educación Artística. Consejo Nacional de la Cultura, Gobierno de Chile. https://wwuw. cultura.gob.cl/wp-content/uploads/2016/02/cuaderno1_web.pdf

Unesco. (2006). Artistica. Conferencia Mundial sobre Educación Artística: construir capacidades creativas para el siglo XXI. http://wuww.unesco.org/ new/fileadmin/MULTIMEDIA/HQ/CLT/CLT/pdf/ Arts_Edu_RoadMap_es.pdf

Unesco. (2010). La Agenda de Seúl: objetivos para el desarrollo de la educación artística. Segunda Conferencia Mundial sobre la Educación Artistica. http://www. unesco.org/new/fileadmin/MULTIMEDIA/HQ/CLT/ CLT/pdf/Seoul_Agenda_ES.pdf 